\title{
Pesquisa exploratória: procedimento metodológico para o estudo de fatores humanos no campo da saúde pública
}

\author{
Exploratory research: a methodological procedure applied to the study of human \\ factors in the field of public health
}

\author{
Armando Piovesan, Edméa Rita Temporini \\ Departamento de Prática de Saúde Pública da Faculdade de Saúde Pública - \\ Universidade de São Paulo - Brasil
}

\begin{abstract}
Propóe-se procedimento metodológico de abordagem qualitativa denominado pesquisa exploratória, cuja aplicaçāo tem por finalidade a elaboraçáo de instrumento de pesquisa adequado à realidade. Discute-se o emprego da expressão "pesquisa exploratória", de um ponto de vista tradicional e nessa nova concepçăo. Fundamenta-se a utilizaçăo desse procedimento metodológico para o estudo de fatores humanos $\theta$ apresentam-se as etapas da sua execuçăo. Sugerem-se indicaçōes para aplicaçắo desse recurso em pesquisas no campo da saúde pública.
\end{abstract}

Pesquisa, métodos. Projeto de pesquisa. Sańde pública.

\section{Introdução}

Para a realização de açðes de saúde pública que dependem do comportamento das pessoas a que se destinam, torna-se de extrema importância conhecer previamente as maneiras de agir, sentir e pensar da comunidade-alvo dessas ações e o contexto onde se insere essa comunidade ${ }^{12}$.

$\mathrm{Se}$ a população pensar que Deus é quem manda a doença, portanto, contra tal desígnio nada há a fazer, ou, que a pessoa se cura somente pela vontade de Deus, quais as açōes preventivas a realizar ou, que mensagens teriam efeito?

As crenças populares, em geral, são fortemente arraigadas e de difícil mudança. Assim, a argumentação técnica a ser utilizada em trabalho dessa natureza deve ser elaborada com base no conhecimento dessas variáveis e na linguagem popular, ao invés da linguagem científica ${ }^{7}$.

Considera-se, portanto, ser tarefa da equipe de saúde a identificaçāo do repertório de conhecimentos e vocábulos comumente empregados pelas pessoas da comunidade. Este constitui o primeiro passo para uma comunicação eficiente.
A experiência tem mostrado que nem sempre o fácil acesso a serviços educativo-assistenciais assegura, por si só, um nível de saúde satisfatório de uma população. Influências restritivas interferem na tomada de decisð̃es e na execução de açőes de saúde, decorrentes de fatores psicossocioculturais. A importância que as pessoas conferem a sua saúde e aos cuidados para preservá-la depende, em especial, de padrōes socioeconômicos, de conhecimentos, hábitos, atitudes e crenças aprendidos culturalmente ${ }^{11}$.

As experiências de vida, ao lado do ensino formal, concorrem para a construção de conhecimentos, crenças, atitudes, valores, emoçōes e motivações, componentes importantes a condicionarem a percepção dos indivíduos acerca de fenômenos biológicos, psíquicos e sócio-ambientais. Assim, a percepção constitui experiência sensorial que adquire significado à luz dessas influências ${ }^{7}$.

Em geral, variáveis relativas à conduta em saúde e seus determinantes oferecem maiores dificuldades metodológicas para sua identificaçāo, compreensão e mensuração. 
Ao se pretender realizar pesquisa sobre fatores humanos, recomenda-se o estudo prévio da realidade, na fase de planejamento da pesquisa, com a finalidade principal de elaborar um instrumento baseado nas experiências reais dos sujeitos, no seu vocabulário e ambiente de vida ${ }^{13}$.

Esse procedimento metodologico, denominado pesquisa exploratória, apresenta natureza qualitativa e contextual.

O objetivo central do presente trabalho consiste emfundamentar e discutir esse recurso metodológico, com a finalidade de facilitar a sua aplicação às pesquisas científicas de variáveis referentes a conduta e seus determinantes, no campo da saúde pública.

\section{A Expressão "Pesquisa Exploratória"}

Inicialmente, cabe distinguir os termos pesquisa exploratória e estudo-piloto (ou pesquisa-piloto).

Piloto, como adjetivo, \& "uma realização em dimensōes reduzidas, para experimentaçāo ou melhor adaptaçāo de certos processos tecnológicos: ensino-piloto, projeto-piloto, laboratório-piloto"; ou, no dizer de Aurélio, piloto é o "que serve de modelo e/ou campo de experimentação para métodos ou processos inovadores: "usina-piloto" ".*" Em Webster ${ }^{* * * *}$, dois conceitos podem ser destacados desse adjetivo:

- "that serves as a guide on guiding device"

- "that serves as a trial unit on a small scale for experimentation or in testing"

Nesse sentido, os termos pesquisa e piloto se repelem, embora, vez por outra, encontre-se a expressão estudo-piloto; neste caso, o termo estudo seria sinônimo de pesquisa.

Quanto ao conceito de pesquisa exploratória, da forma como é tradicionalmente entendida, quem melhor o descreve é Theodorson e Theodorson ${ }^{14}$.

"Exploratory study. A preliminary study the major purpose of which is to become familiar with a phenomenon that is to investigate, so that the major study to follow may be designed with greater understanding and precision. The exploratory study (which may use any of a variety of techniques, usually with a small sample) permits the investigator to define his research problem and formulate his hypothesis more accurately. It also enables him to choose the most

* Dicionario Melhoramentos da lingua portuguesa. Sāo Paulo, Meihoramentos, 1977.

** Novo diciondrio da língua portuguesa. $2^{a}$ ed. Rio de Janeiro, Nova Fronteira, 1986.

*** Webster's New Twentieth Century of the English Language. Unabridged. 2nd ed. Cleveland, The World Publ., 1965. suitable techniques for his research and to decide on the questions most in need of emphasis and detailed investigation, and it may alert him to potential difficulties, sensitivities, and areas of resistance."

São relativamente raros os textos de metodologia científica que têm consideraçð̌es sobre o citado termo. Menos freqüentes, ainda, são as mençס̄es sobre pesquisas exploratórias realizadas como recurso adicional da pesquisa principal.

Dos vários textos que versam sobre esse assunto, destacam-se alguns, a seguir.

Polit e Hungler" dizem, sobre o termo "exploratory research": "A preliminary study designed to develop or refine hypothesis, or to test and define the data collection methods". "Exploratory study is an extension of descriptive research."

Detalhando mais, dizem:

"Researchers may engage in exploratory research for two basic reasons. First, the investigator may be simple curious and desire a richer understanding of the phenomenon of interest than a straight forward descriptive study could provide. This reason is particularly salient when a new area or topic is being investigated, for which no satisfactory theory can be identified. Second, exploratory studies are sometimes conducted to estimate the feasibility and cost of undertaking a more rigorous or extensive research project on the same topic. When largescale studies are antecipated, it is usually wise to explore potential difficulties with a smaller version of the study."

Outro texto que versa sobre o assunto é o editado por Babbie ${ }^{1}$, que assim se expressa:

"Much of social research is conducted to explore a topic, to provide a beginning familiarity with that topic. This purpose is typical when a researcher is examining a new interest or when the subject of study is itself relatively new and unstudyied."

Uma das características da pesquisa exploratoria, tal como é geralmente concebida, refere-se à especificidade das perguntas, o que $e$ feito desde o começo da pesquisa, como única maneira de abordagem. Parailustrar este aspecto, retoma-se Babbie ${ }^{1}$ :

"As an example, let's suppose that a widespread taxpayer dissactisfaction with the government events into a taxpayer's revolt. People begin refusing to pay their taxes and they organize themselves around that issues. You might like to learn more about the movement: How widespread is it? What levels and degrees of support are there within the community? How is the 
movement organized? What kinds of people are active in it? You might undertake an exploratory study to obtain at least approximate answers to some of these questions."

Babbie resume as finalidades da pesquisa exploratória dizendo:

"Exploratory studies are most typically done for three purposes: (I) simply to satisfy the researcher's curiosity and desire for better understanding, (2) to test the feasibility of undertaking a more careful study, and (3) to develop the methods to be employed in a more careful study."

O estudo exploratório pode ajudar a resolver algumas dificuldades em pesquisa. Uma delas $\varepsilon$ a que se refere ao desenvolvimento de programas, na concepção de que a população constitui um recipiente vazio ("empty vessel") e que a tarefa educativa se resumiria em preenchê-lo. Nada mais que um engano, pois a população é rica de conhecimentos e esses conhecimentos, opiniões, valores e atitudes é que vão se constituir, muitas vezes, em barreiras. Essas barreiras podem ser conhecidas por meio do estudo exploratório e, pelo menos, parcialmente contornadas, a fim de que o programa educativo alcance maior aceitação. Não é outra a opinião de Ross e Rosser ${ }^{10}$.

"In addition to these models of what may enhance health education, there are also a number of illusions that must be noted. Green et al (1980) refer to the 'empty vessel fallacy', in which educators behave as if all they have to do to ensure the success of their programs is to pour information into the empty minds of the target population".

Nesse enfoque, a pesquisa constituiria o passo inicial a subsidiar o planejamento de programas de saúde direcionados para a mudança de comportamento de indivíduos ${ }^{12}$.

\section{Fundamentos da Pesquisa Exploratória}

A pesquisa exploratória, da maneira proposta neste trabalho, apoia-se em determinados princípios bastante difundidos: 1) a aprendizagem melhor se realiza quando parte do conhecido; 2 ) deve-se buscar sempre ampliar o conhecimento e 3) esperar respostas racionais pressupõe formulação de perguntas também racionais.

"Pergunta racional" merece uma referência especial em termos do enfoque dado a este trabalho.

É costume, na área das ciências da saúde, considerar-se o termo racional como aquele baseado nos conhecimentos científicos; estes são os certos. De outro lado, o que não se conforma com tais conhe- cimentos, considera-se errado ${ }^{6}$.

Neste caso, as respostas seriam consideradas certas porque se conformam com o Repertório Profissional de Respostas, ou seja, com o universo de explicações científicas.

"Enquanto a terminologia médica é essencialmente precisa e restrita, a popular, além de vaga, apresenta uma riqueza prodigiosa de palavras a respeito de uma doença, que varia de país para país, de regiăo para regiāo e, também, em cada comunidade e classe social; além disso, a medicina popular conta com entidades mórbidas, que nāo encontram correspondente no campo da medicina científica (mau-olhado, por exemplo)" 6 .

Mas, há uma forma alternativa de se considerar o conhecimento popular como certo. Neste caso, o conhecimento será tido como certo se se coadunar com o Repertorio Popular de Respostas, ou seja, com o universo de explicaçóes populares.

Fazer perguntas racionais para receber respostas racionais implica fazer perguntas congruentes com - Repertório Popular de Respostas: as respostas serão "lógicas", segundo esse entendimento, se se coadunarem com este Repertório. Assim, as respostas estariam de conformidade com a "realidade".

Desse modo, ao contrário do que é considerado certo pela práxis, fazer perguntas racionais, para receber respostas racionais, implica saber fazer perguntas adequadamente "racionais" em termos do Repertório Popular de Respostas.

Negar essa realidade, menosprezá-la ou ignorála, sob o pretexto de que não apresenta qualquer significado de valor, é aumentar a probabilidade de se colher resultados negativos na tarefa educativa.

A realidade educativa com que os técnicos por vezes lidam sói ignorar simplesmente o Repertório Popular de Respostas, sob a alegação de que as pessoas são ignorantes. $O$ emprego de questionários não-estruturados (contendo apenas perguntas, sem previsão das respostas), além das dificuldades conhecidas que apresentam, não conduzem ao âmago do Repertório Popular de Respostas; permite, apenas, que se o aflore superficialmente, de forma irregular, errática e distorcida. Nessas condições, a metodologia empregada é inadequada para abordar esse modelo de repertório.

Em resumo, o que pode parecer racional à luz do Repertório Profissional de Respostas, pode ser irracional e inadequado quando se tem em vista que o modelo a seguir seria o do Repertório Popular de Respostas. A técnica de abordagem para se conhecer um dos repertórios costuma ser inapropriada para conhecer o outro.

Quando se aplica um questionário pré-estabelecido (estabelecido antes de se conhecer a realidade, ou seja, antes de se conhecer o Repertório Popular de Respostas), costuma-se distorcer os resultados. 
Pode-se dizer, então, que, para se obter determinada resposta, é preciso fazer a pergunta correspondente. Além disso, para se obter "boas" respostas é preciso fazer-se "boas" perguntas. Mas para fazer "boas perguntas", ou perguntas pertinentes e de interesse, é preciso conhecer com antecipação as possf́veis respostas, que consistiriam no "Universo de Respostas".

Cai-se, portanto, num círculo vicioso: Para obter "boas" respostas preciso fazer "boas" perguntas. Para fazer "boas" perguntas precisa-se conhecer as respostas que as perguntas podem suscitar. O problema, então, está em sair desta circularidade. No Universo de Respostas há n respostas, umas melhores ou mais pertinentes que outras. Há respostas mais válidas e menos válidas. O problema está em identificá-las. Por exemplo, pretende-se medir o conhecimento popular sobre a etiologia do câncer ginecológico. Como perguntar para saber o que as pessoas sabem a esse respeito, dentro do Repertório Popular de Respostas, como elas sentem e reagem, suas atitudes, suas opiniōes?

A soluçảo do problema está, pois, em elaborar um instrumento de medida capaz de captar, do Universo de Respostas, as respostas mais adequadas ou convenientes para a pesquisa. Quanto mais ajustado à realidade, mais capaz será o instrumento de relatar com precisão as melhores respostas.

Assim, o problema de elaborar um bom instrumento de medida se transfere para busca de um melhor conhecimento do Universo de Respostas. Quanto melhor o conhecimento do Universo de Respostas, mais capacitado está o pesquisador em elaborar um bom instrumento de pesquisa. E ele será um bom instrumento, na medida em que for capaz de fazer boas perguntas.

Do exposto, depreende-se ser esta concepção consideravelmente distante dos entendimentos de praxe, apresentados por outros autores retro-mencionados. Esse afastamento se refere não só a pormenores, mas também a aspectos básicos, essenciais; $\dot{e}$ suficientemente palpável para se afirmar que a expressão "pesquisa exploratória" pode ser aplicada a realidades distintas.

\section{A Pesquisa Exploratória como Recurso Metodológlco}

Define-se pesquisa exploratória, na qualidade de parte integrante da pesquisa principal, como o estudo preliminar realizado com a finalidade de melhor adequar o instrumento de medida à realidade que se pretende conhecer.

Em outras palavras, a pesquisa exploratótia, ou estudo exploratório, tem por objetivo conhecer a variável de estudo tal como se apresenta, seu signi- ficado e o contexto onde ela se insere. Pressupõe-se que o comportamento humano é melhor compreendido no contex to social onde ocorre ${ }^{9}$. Nessa concepção, esse estudo tem um sentido geral diverso do aplicado à maioria dos estudos: é realizado durante a fase de planejamento da pesquisa, como se uma subpesquisa fosse e se destina a obter informação do Universo de Respostas de modo a refletir verdadeiramente as características da realidade. Assim, tem por finalidade evitar que as predisposiçóes não fundadas no repertorio que se pretende conhecer influam nas percep̧̧ðes do pesquisador e, consequientemente, no instrumento de medida. Não corrigido, este tipo de tendência poderá conduzir o pesquisador a perceber a realidade segundo sua ótica pessoal, de caráter técnico-profissional. A pesquisa exploratória, permitindo o controle dos efeitos desvirtuadores da percepçăo do pesquisador, permite que a realidade seja percebida tal como ela é, e nāo como o pesquisador pensa que seja.

Enquanto, segundo as concepçōes tradicionais, a pesquisa exploratória tem por finalidade o refinamento dos dados da pesquisa e o desenvolvimento e apuro das hipóteses, nesta nova concepçåo é realizada com a finalidade precípua de corrigir o viés do pesquisador e, assim, aumentar o grau de objetividade da própria pesquisa, tomando-a mais consentânea com a realidade.

Nesse sentido, a pesquisa exploratória leva o pesquisador, frequentemente, à descoberta de enfoques, percepçōes e terminologias novas para ele, contribuindo para que, paulatinamente, seu proprio modo de pensar seja modificado ${ }^{6}$. Isto significa que ele, progressivamente, vai ajustando suas percepções à percepção dos entrevistados. Em outras palavras, ele vai conseguindo controlar, quase que imperceptivelmente, o seu viés pessoal.

Pode-se constatar a subsistência desta proposiçāo se se considerar, por exemplo, que se deseja conhecer os fatores da prole numerosa ou do controle de natalidade. É inegável que existem diferenças, às vezes pronunciadas, entre as concepções científicas e as concepções populares. E que estas diferenças sảo desconhecidas e podem operar consequiências importantes, redundando, ao final, em distorçōes apreciáveis e significativas. Essa prática do pesquisador, realizando a pesquisa definitiva com base em suas próprias concepções, pode levar a falsas concepç⿸丆es, em que os pontos de vista e as motivaçôes pessoais, de caráter profissional, predominam.

Resumindo, duas diferenças básicas distinguem as pesquisas exploratórias realizadas segundo o procedimento tradicional e da forma aqui proposta.

- No modelo tradicional, há uma projeção da mente do pesquisador no que está sendo observado ou perguntado, o que é feito através de perguntas específicas. Essas perguntas conferem direçāo à 
pesquisa. Dessa forma, a pesquisa principal, embora passe a contar com mais informaçōes e mais detalhes, ela, no seu conjunto, nāo é outra coisa que a mente do pesquisador projetada na pesquisa.

- Na forma proposta, há um esforço grande do pesquisador para controlar os efeito distorcivos de sua subjetividade naquilo que está sendo perguntado. A subjetividade não pode ser totalmente controlada, mas o que importa é o grau de controle possível de ser feito. Esse esforço é tão mais intensivo quanto mais no início se está na pesquisa.

A pesquisa exploratória, assim norteada, integra-se ao planejamento da pesquisa principal. Constitui parte dela e nāo subsiste por si ś6. E um meio simplesmente, mas um meio muito importante para mostrar a realidade de forma verdadeira.

Torna possível estruturar totalmente as questðes do instrumento da pesquisa, ou seja, construir as perguntas e as respostas pertinentes, com base nas informaçỏes que emergiram da própria populaçāo.

Trata-se de procedimento que muito exige do pesquisador, desde que se torna necessário apreender e transferir para o instrumento os significados e o vocabulário conferidos pelos indivíduos ao objeto de estudo.

O estudo exploratório permite, portanto, aliar as vantagens de se obter os aspectos qualitativos das informações à possibilidade de quantificá-los posteriormente. Esta associação realiza-se em nível de complementaridade, possibilitando ampliar a compreensão do fenômeno em estudo ${ }^{4}$.

Acredita-se, portanto, que o emprego equilibrado de metodologias qualitativas e quantitativas permite ampliar a compreensāo acerca de determinada realidade ${ }^{5,9}$. Embora, de um ponto de vista epistemológico e metodológico possam existir diferenças marcantes, não se considera haver oposição frontal entre as citadas abordagens. Nesse sentido, referenda-se a afirmação de Leitâo ${ }^{2}$, a respeito do "sentido ético possível de ser encontrado na associação de métodos quantitativos e qualitativos de pesquisa, cujo fim último deveria ser a busca de melhorias de vida dos seres humanos."

\section{Operacionalização da Pesquisa Exploratória}

Operacionalmente, pode-se descrever o estudo exploratório como constituindo um "continuum" que, partindo de uma situaçăo de pouco ou nenhum conhecimento do Universo de Respostas, alcance a condição de um conhecimento qualitativo autêntico desse mesmo universo.

Esse estudo é realizado em várias etapas; cada uma delas apresenta finalidade e metodologia próprias. No conjunto, as etapas constituem trabalho harmônico e coordenado. Cada etapa se apbia nos resultados obtidos na etapa anterior. Não existe um número pré-determinado de etapas; serão realizadas tantas quantas forem necessárias, até a elaboração de um instrumento totalmente estruturado ${ }^{13}$.

A primeira etapa consiste em realizar entrevistas em profundidade e não-dirigidas, nas quais, evitando-se perguntas que possam dirigir respostas para o que se tem em mente, procura-se dialogar com o entrevistado dentro de um campo descontraído, em que se propicia o máximo de liberdade de expressão ${ }^{15}$. Esse tipo de entrevista tem por finalidade obter o máximo de informações que o indivíduo entrevistado possa oferecer. Nesta fase, costumase usar um roteiro para as entrevistas, contendo apenas tópicos sobre os quais se pretende conversar. Contudo, se no decorrer das entrevistas verificar-se que a conversa toma rumos diferentes, porém pertinentes ao objeto de estudo e interessantes para a pesquisa, năo se deve hesitar em modificar o roteiro planejado.

A entrevista em profundidade não dirigida é de difícil realização, requerendo experiência do pesquisador porque, além da habilidade de fazer o respondente falar livremente e de dar informaçōes, deve evitar induzi-lo a manifestar idéias que não são as suas. Deve, além disso, procurar verificar o que é real no mundo do respondente evitando, para isso, "filtrar" o que vê ou ouve através das lentes subjetivas de sua própria personalidade. Deve, também, reavaliar continuamente o que é importante e o que nāo é importante, tendo em vista o tema da pesquisa.

Quanto ao objeto que se tinha primordialmente em mente para o assunto, podem ocorrer sucessivas modificações, seja pela incorporação de aspectos antes desconhecidos pelo pesquisador, seja pela reformulação dos previamente conhecidos.

As entrevistas em profundidade e nāo dirigidas podem ser realizadas com um só respondente ou em grupos de 3 a 6 respondentes. As entrevistas individuais ou em grupo oferecem vantagens e desvantagens que se complementam reciprocamente. Daí, a vantagem de associá-las ${ }^{3}$.

As entrevistas devem, de preferência, ser gravadas.

O material colhido costuma ser abundante e bastante diversificado, ficando difícil perceber-se uma linha condutora. À medida que se acumulam os registros de relatos, toma-se difícil ou impossível lembrar quais dos registros contêm ou não informações sobre determinado tópico.

Algum sistema classificatório é essencial para que o investigador evite perder muitas horas a procurar, em suas anotaçzes, alguns itens que lembra vagamente mas que nāo pode localizar.

O sistema de classificaçāo deve ser adaptado ao objeto da pesquisa, de forma que aqui nāo é possível apresentar regras específicas. Mas, à medida que a pesquisa se torna mais claramente focalizada, o 
pesquisador pode criar um sistema mais complexo de classificação.

Para solucionar o problema do grande acervo de dados, o que toma esta fase de difícil equacionamento, disforme, iregular, dispersa, recomenda-se classificar o material disponivel tomando como fio condutor o objeto de pesquisa. Assim, não só os dados passam a ser ordenados, como também escoimados dos assuntos irrelevantes. O que sobra é um material ainda bruto, mas já com contornos inteligíveis.

Esta fase da pesquisa, a primeira, termina com a saturação do assunto. Esta condição demonstra que se chegou ao "fundo do poço".

Na etapa seguinte da pesquisa exploratória, procura-se burilar os dados, fazendo-se perguntas especificas - ou melhor, cada vez mais específicas - para aperfeiçoar certos dados ou para obter conhecimentos novos. Nestes se incluem, também, conhecimentos do repertório profissional - introduzidos em fase mais avançada - os quais vão se teunir aos do repertório popular formando um todo único.

Se determinados aspectos não ficaram devidamente esclarecidos ou permaneceram omissos, admite-se que se repita a primeira fase para resolver especificamente este problema.

Nas etapas subsequientes, o objetivo é apurar sempre mais os resultados obtidos e rever a classificação dos dados.

A seguir, os dados são colocados sob a forma de perguntas e respostas. Isto é possível porque já se domina praticamente todo, ou quase todo, o universo de respostas.

As perguntas e respostas são progressivamente aperfeiçoadas através de sucessivas aplicaçōes.

A pesquisa exploratória pode ser realizada em uma so etapa, embora raramente isto aconteça, ou, então, pode ser a etapa fínal de uma sucessão de etapas preliminares, em número raramente maior que 10; geralmente, 5 ou 6 .

Esse número varia em função de vários problemas, como, complexidade da pesquisa, desconhecimento maior ou menor do Universo de Respostas, colaboração maior ou menor da população, grau de habilidade do pesquisador, amplitude do campo de pesquisa e qualidade dos dados a serem obtidos. Quanto mais desconhecido o Universo de Respostas, mais provável ser maior o número de etapas. E recomendável entrevistar pessoas diferentes em cada etapa, a fim de obter novas informações e, assim, ampliar o Universo de Respostas.

Párá-se no momento em que se começa a receber as mesmas respostas. Daí para frente, as novas respostas vão se tornando cada vez menos freqüentes e, por isso, vão tendo cada vez menos interesse.

Na última etapa aborda-se $o$ aspecto quantitativo da pesquisa exploratória. Nessa etapa, o questionário, praticamente estruturado, é aplicado a uma amostra de, geralmente, tamanho 30 . A seguir, é feita completa revisão do questionário, visando ao seu aperfeiçoamento e à eliminação de questões que se mostraram de pouco interesse do ponto de vista quantitativo. Especificamente, deve-se melhorar as respostas, respostas que equivalem às categorias da variável. Devese procurar apurar melhor os aspectos formais das questōes, o que se fará, em grande parte, aplicando os princípios da categorização de variáveis.

Nāo se pode esquematizar com precisāo as etapas da pesquisa exploratória, pois elas dependem de numerosos fatores aleatórios. Contudo, pode-se dizer que a pesquisa exploratória pode ser agrupada, grosseiramente, em etapas que se superpōem, nas seguintes etapas principais.

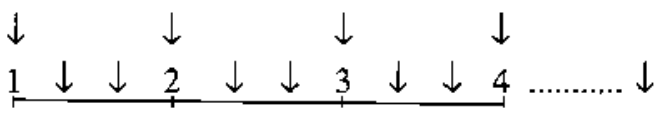

$\begin{array}{llll}\text { Entrevistas } & \text { Entrevistas Classificação } & \text { Elaboração } & \text { Pré- } \\ \text { em profundi- com questio- do material } & \text { de questio- } & \text { teste } \\ \text { dade e não- } & \text { nário não- obtido } & \text { nário es- } & \\ \text { dirugidas } & \text { estruturado } & & \\ & \text { ou semi-es- } & & \\ & \text { truturado } & & \end{array}$

$\downarrow$ etapa exploratória realizada; seu número nāo pode ser antecipadamente determinado.

Não se deve confundir pesquisa exploratória com pré-teste.

O pré-teste se limita a um aperfeiçoamento do questionário quanto à sua forma. Quando se faz pesquisa exploratória, o pré-teste passa a ser parte integrante dela, nela estando embutido. Nestas condiçōes, as questões de forma já vão sendo resolvidas, nāo havendo, praticamente, necessidade de alterações.

\section{Indicaçōes da Pesquisa Exploratória}

Dentre as várias possíveis aplicaçoes da pesquisa exploratória pode-se enumerar algumas indicaçōes.

1. Identificaçâo do Nome da Doença - A identificação do nome da doença constitui-se em informação básica, pois a pesquisa depende de comunicaçāo clara e eficaz. E a comunicação deve ser feita em termos dos nomes que fazem parte do Repertório Popular e não do Repertório Profissional. Deve-se levar em consideraçăo o conhecimento popular dos referentes científicos. Sem isso, a comunicação com a maioria dos respondentes ficaria impossivel ou equívoca ${ }^{6}$.

Exemplificando, o termo blenorragia deve ter 
pequena penetração popular. Tem-se, em compensação, uma grande variedade de sinônimos: gonorréia, esquentamento, pingadeira, doença do canal, doença da rua, doença da vida, doença do homem (e da mulher), purgação, gota matutina, fogagem e outros, utilizados popularmente.

\section{Conhecimento do Repertório Popular de Respos-} tas - Esta é a finalidade primordial da pesquisa exploratória. O Repertório Popular de Respostas tanto pode se referir ao conhecimento, crença e opiniāo, como à atitude, aos valores e à conduta.

Quando a pesquisa se refere a uma doença ela deverá, de preferência, referir-se ao conhecimento de, por exemplo, causas, transmissāo, diagnóstico, tratamento, prevenção, gravidade, suscetibilidade, sequielas, entre outros.

Mas não são apenas as doenças que são suscetíveis de serem estudadas por pesquisa exploratória. Todos os assuntos cujo enfoque popular seja mal conhecido, ou conhecido por outra forma, podem ser pesquisados. Pode-se lembrar, nesse sentido, pesquisas sobre alimentação, exercícios físicos, acidentes, contraceptivos, alcoolismo, drogas e fumo, entre outros.

\section{Elaboração de Questionário Ajustado à Realidade}

- Esta vantagem, como se depreende, é decorrente do progressivo melhoramento do questionário, resultante do processo de aprimoramento desse instrumento de medida.

O questionário final será totalmente estruturado, o que representa, ponderados os prós e contras, inegável vantagem. Convém lembrar que, devido à pesquisa exploratória ele incorpora também as vantagens dos questionários constituídos de questões abertas.

4. A pesquisa exploratória contribui para que se conheça melhor as características da população $e$, assim, planejar mais eficientemente o tamanho amostral. É também, devido ao melhor conhecimento da população que se pode verificar qual a forma de aplicação mais adequada do instrumento, se por auto-aplicação ou por entrevista.

5. Permite, também identificar/categorizar de forma adequada certas variáveis independentes mais complexas, principalmente no que tange à aplicação do princípio da utilidade.

\section{Considerações Finais}

Em suma, a pesquisa exploratoria permite um conhecimento mais completo e mais adequado da realidade. Assim, o aivo é atingido mais eficientemente, com mais consciência. A pesquisa exploratória corresponderia a uma visualização da face oculta da realidade. Esta corresponde ao Universo de Respostas, desconhecido. Esta face seria iluminada pela pesquisa exploratória.

Cumpre ressaltar, finalmente, que a pesquisa exploratória não é uma panacéia e nem apresenta utilização plenamente assegurada. O seu emprego sofre muitas limitaçōes, de tal modo que se adota o seguinte critério para sua indicação:

- Tem sua aplicaçāo limitada aos "surveys". Nos experimentos tem pouco uso.

- Deve ser necessária, ou seja, deve ter indicação precisa. $O$ que nem sempre ocorre. Uma pesquisa realizada dentro de um contex to exclusivamente profissional, torna desnecessário o uso do contexto popular.

- Deve-se dispor de tempo para realização da pesquisa exploratória.

- Deve haver compensação para o tempo investido e o maior custo da pesquisa. Esse tempo adicional deve ser compensado pela maior eficácia da pesquisa.

\section{Reterências Bibliográflcas}

1. BABBIE, E. The practice of social research. 4 th ed. Belmont, Wadsworth Publ., 1986.

2. LEITÃO, C. Debate sobre 0 artigo de Minayo \& Sanches. Cad. Saude Pública, 9: 257-8, 1993.

3. LÜDKE, M. \& ANDRE, M. E. D. A. Pesquisa em educą̧āo: abordagens qualitativas, Såo Paulo, EPU, 1986.

4. MINAYO, M. C. de S. \& SANCHES, O. Quantitativo-qualitativo: oposiçāo ou complementaridade? Cad. Saúde Pública, 9: 239-62, 1993.

5. MULLEN, P. D. \& IVERSON, D. Qualitative methods for evaluative research in health education programs. Health Educ., 13 (3): 11-18, 1982.

6. PIOVESAN, A. Da necessidade das escolas de saúde pública elaborarem métodos simplifiçados de investigação social. S. Paulo, 1968. [Tese de Doutorado - Faculdade de Saúde Pública da USP].

7. PIOVESAN, A Percepçðo cultural dos fatos sociais: suas implicaçòes no campo da saúde pública. Rev. Saúde Püblica, 4: 85-97, 1970.

8. POLIT, D. F. \& HUNGLER, B. P. Nursing research:principles and methods. 3rd ed. Philadelphia, J. B. Lippincott, 1987.

9. QUEIROZ.M.I.de P.O pesquisador, o problema da pesquisa, a escolha de técnicas: algumas reflexðes. In: Lang, A.B.S.G., org. Reflexōes sobre a pesquisa sociologica. Sao Paulo, Centro de Estudos Rurais e Urbanos, 1992. p. 13-29. (Coleçāo Textos; 2" série, 3).

10. ROSS. M. W. \& ROSSER, B. R. S. Education and AIDS risk: a review. Health Educ, Res., 4: 273-84, 1989.

11. TEMPORINI, E. R. Ação preventiva em problemas visuais de escolares. Rev. Saúde Pública, 18: 259-62, 1984.

12. TEMPORINI, E. R. Pesquisa de oftalmologia em saúde pública: consideraçōes metodológicas sobre fatores humanos. Arq. Bras. Oftal., 54: 279-81, 1991.

13. TEMPORINI, E. R. Saúde do escolar: conduta e opiniăo de professores do sistema de ensino do Estado de São Paulo, Săo Paulo, 1986. [Tese de Doutorado - Faculdade de 
Saúde Pública USP].

14. THEODORSON, G. A. \& THEODORSON, A. G. A modern dictionary of sociology. London, Methuen, 1970.

15. TRIGO, M, H. B. \& BRIOSCHI, L. R. Interação e comunicaçăo no processo de pesquisa. In: Lang, A. B. S. G., org. Reflexöes sobre a pesquisa sociologica. Săo Paulo, Centro de Estudos Rurais e Urbanos, 1992. p. 30-41. (Coleção Textos; $2^{*}$ série, 3 ).

\section{Abstract}

Exploratory research is proposed as a methodological procedure for a qualitative approach. The main purpose of this procedure is that of helping the researcher to develop a measurement tool which reflects reality. Both exploratory research conceptions, the traditional and the new one are discussed. The application of this methodological procedure to the study of human factors is recommended and the implementation stages are presented. Some applications for research in public health are suggested.

Research, methods. Research design. Public health. 